\title{
Cristina Urchueguía
}

\section{Die Erfindung der spanischen Musik - Autorität als Baustein nationaler Identität am Beginn des »Goldenen Jahrhunderts«}

Todo nombre, dize el philosopho que significa muchas cosas, si del se tracta sin diuidirlo: causa gran confusion. ${ }^{1}$

Juan Bermudo, 1555

Jeder Name, behauptet der Philosoph, bedeutet viele Dinge, wenn man sich mit ihm beschäftigt, ohne ihn aufzuteilen, entsteht große Verwirrung.

Bermudos Diktum führt uns die aporetische Spannung, die im Begriff Autorität eingeschrieben ist, vor Augen, bedient er sich doch der Autorität des Philosophen, um die Bedeutung von Namen, auch die des Philosophen, zu problematisieren. Schon die Wurzel des Begriffes - der Autor - bezeichnet sowohl den Urheber und Gewährsmann als auch den Namen, unter dem etwas verwahrt und katalogisiert wird. In Ausnahmefallen ist der Autor gleichbedeutend mit einem >Qualitätssiegek. Fügt man das Suffix hinzu und lässt den Autor zur >Autorität< werden, begegnet uns dieser in einer bestimmten Funktion, die nur im Zusammenhang mit der Rezeption ergründet werden kann. Der Begriff Autorität stellt eine unlösbare Verknüpfung zwischen Autorbegriff, Gesellschaft und Geschichte her. Autoritäten sind zu beschreiben als eines der Instrumente, derer sich eine bestimmte Gesellschaft bedient, um ihr Geschichtsbild zu konturieren und zu stabilisieren. Es fragt sich nur, zu welchem Zweck die Festsetzung und die Beschwörung von Autoritäten stattfindet und ob die Nutzung der Waffe >Autorität in dem beabsichtigten Sinn erfolgreich ist - zwei Fragen, die ich in Verbindung mit einem zweiten Namen stellen möchte: Spanien.

Auch dieser Name bezeichnet im ausgehenden 15. und im 16. Jahrhundert keinen einfachen Sachverhalt. Einige Eckdaten dazu:

1 Juan Bermudo, Libro llamado declaracion de instrumentos musicales, Ossuna 1555, fol. $121^{\text {t }}$. 


\section{Wie es zu Spanien kam}

Bis 1492 sind auf der iberischen Halbinsel drei Religionen vertreten: Juden und Christen leben in Mittel- und Teilen von Südspanien sowie am Mittelmeer. Granada steht unter arabischer Herrschaft. Politisch bestehen auf der iberischen Halbinsel neben dem Emirat von Granada die Königreiche Aragón, Portugal, Kastilien und Navarra, ferner relativ unabhängige Herzogtümer in Katalonien und Valencia. Sizilien, Sardinien und Neapel befinden sich unter aragonesischer Herrschaft. Aragón schaut von jeher ins Mittelmeer. Kastilien lenkt seinen Blick in Richtung Atlantik und versucht, Portugal über dynastische Beziehungen an sich zu binden.

Im Norden, an der kantabrischen Küste, spricht man Baskisch, im Nordwesten und Westen wird Galizisch und Portugiesisch gesprochen, die Bewohner der Mittelmeerküste und der Balearen sprechen verschiedene Dialekte des Katalanischen. Kastilisch oder romance, die Sprache, die zur heutigen Landessprache geführt hat, ist im Innenland, auf der Meseta central beheimatet.

1469 werden die Weichen für eine durchgreifende Neustrukturierung gestellt, nach dem Motto: „Felix Hispania nube!« Ferdinand II. von Aragonien und Isabella I. von Kastilien, die künftigen »Reyes Católicos«, heiraten. Oberstes Gebot ihrer Politik ist die Zusammenführung aller Teile der iberischen Halbinsel unter eine politische Führung. Man könnte meinen, dies sei gleichbedeutend mit einer Rückkehr zum Status quo vor der Eroberung der Halbinsel durch die Araber 711. Damals stand Spanien jedoch unter westgotischer Herrschaft, davor unter römischer, davor gab es karthagische und phönikische Kolonisierungen, Kelten und Griechen siedelten ebenfalls auf der iberischen Halbinsel. Es gibt keine Völkerwanderung, keine imperialistische Ausbreitungspolitik, die das Gebiet ignoriert hätte. Der Kampf gegen wechselnde Besatzungen lässt sich bis weit in vorchristliche Zeit zurückführen. Nicht eine Rückkehr stellt die Vereinigung der Königreiche dar, sondern das Ende des Kampfes um die Befreiung Spaniens.

Der symbolische Feind des 15. Jahrhunderts, die Araber, gebietet eine sekundäre, ideologische Kampfstrategie: die religiöse Vereinheitlichung, also die Christianisierung des Landes. Die Einnahme Granadas samt Vertreibung der Juden und Araber erfolgte 1492. Die Wiederbelebung der Inquisition 1481 erwies sich insofern als weise Voraussicht, als diese der kastilisch-aragonesischen Krone unmittelbar unterstand. Die "Katholischen Könige" hatten vom spanischen Papst Alexander VI. die Erlaubnis erhalten, eigenmächtig Bischöfe zu ernennen. Sie waren in der Lage, die Inquisition zum durchschlagenden Werkzeug für die religiöse und ethnische Säuberung nach $\mathrm{Maß}$ zu gestalten. Nach 
dem Tod Isabellas 1504 herrscht ihr verwitweter Gemahl Ferdinand in Personalunion über beide Königreiche. 1512 schließt sich das Königreich Navarra der Vereinigung von Aragonien, Granada und Kastilien an.

Eine Herrschergeneration wurde aus verschiedenen Gründen übersprungen. 1517 trat Karl V. das Erbe seines 1516 verstorbenen Großvaters an. Er herrschte als erster spanischer König über eine - sieht man von Portugal ab - politisch vereinigte iberische Halbinsel. Die Nation Spanien erstreckte sich jedoch zu diesem Zeitpunkt weit über diese geographischen Grenzen hinaus. 1492 erreichte Christophorus Columbus dank kastilischer Finanzierung und in kastilischem Auftrag "Las Indias«. Dass der Entdecker Amerikas, will man der Legende glauben, an die weltgeschichtliche Relevanz seiner Entdeckung nie glauben mochte, hinderte Portugiesen und Spanier nicht daran, die Gebiete jenseits des Atlantiks zu erobern, unter sich zu verteilen und auszubeuten. Der 1494 unterschriebene Vertrag von Tordesillas legte die Grundlinien der künftigen politischen Struktur in Amerika fest, darüber hinaus beugte er den zu erwartenden Zwistigkeiten zwischen den Seefahrernationen vor. ${ }^{2}$ Kaum, dass politische Einheit oder >Quasi-Einheit< auf der iberischen Halbinsel herrschen, stellt sich die Sachlage folgendermaßen dar: Ein burgundischer Kaiser, der nicht einmal Spanisch spricht, regiert ein Land, dessen Grenzen jeden Tag anders werden.

Wir wohnen in den Jahren zwischen 1469 und 1516 der Geburt einer Nation bei, deren Geschichte, gesellschaftspolitische Struktur und kulturelles Selbstverständnis integrative, aber auch zersetzende Momente aufweist. Dieser Prozess hätte nur ein unterdeterminiertes und instabiles Gebilde hervorgebracht, wenn er die politische Neuordnung des geographischen Raums nicht auf ein kulturhistorisches Substrat hätte gründen können.

Eine auf die Nationalität begründete kulturelle Identität lässt sich auch im Moment ihrer Entstehung als Spezialfall des Phänomens der Tradition und des kollektiven Gedächtnisses beschreiben, die Idee der Nation ist stets auf überindividuelle, historische, transzendente Legitimation angewiesen. ${ }^{3}$ Eine nationale Tradition wiederum kristallisiert sich in einem dynamischen Prozess heraus, in dem bestimmte privilegierte Aspekte des kollektiven Gedächtnisses gestaltet, gebündelt und intepretiert werden, um als intersubjektiv geltende Projektionsfläche für die Identifikation des Individuums mit der Gemeinschaft, in diesem

2 In dem Vertrag von Tordesillas erkannte Portugal die Geltung der von Papst Alexander VI. formulierten Bulle »Inter caetera divinae« von 1493 an. Diese Bulle legte eine Seescheide fest, die die Zuordnung der Gebiete in Übersee an Spanien oder Portugal regulierte.

3 Siehe dazu Zofia Lissa, "Prolegomena zur Theorie der Tradition in der Musik», in: Archiv für Musikwissenschaft 27 (1970), S. 153-172. 
Fall mit der Nation, zu fungieren. ${ }^{4}$ Das kulturelle Gedächtnis steht im engen Zusammenhang mit Kanonisierungs- und Entkanonisierungsprozessen, mit der Definition bestimmter Geschichtsmodelle bzw. der Konstruktion eines verbindlichen Selbstbildes und last but not least mit der Verknüpfung der nationalen Geschichtsrekonstruktion mit einer ebenfalls nationalen Hagiographie und $\mathrm{Hel}$ dengalerie - oder anders formuliert, mit der Zuordnung nationaler Tugenden und Ereignisse nationaler Relevanz zu Individuen, die diese sinnfällig personifizieren: tote, lebende, mythologische, religiöse Figuren, die den nationalen $\mathrm{Ge}$ danken im Pantheon, in der Politik und der Universität, in der Poesie, der Musik, der Kunst und der Kirche repräsentieren. Im Begriff der Autorität konkretisieren sich die Elemente der nationalen Identität in anschaulicher Form, die Vorbildfunktion der Autorität wird greifbar, benennbar, operationalisierbar.

Nun geht die Diskussion um Tradition und um kulturelles Gedächtnis stets von stabilen sozialen und politischen Gefügen aus. Ihre Stichwörter sind Kontinuität, Überdauern, Stabilität, retrospektive Besonnenheit.

Das kulturelle Gedächtnis hat seine Fixpunkte, sein Horizont wandert mit dem fortschreitenden Gegenwartspunkt mit. Diese Fixpunkte sind schicksalhafte Ereignisse der Vergangenheit, deren Erinnerung durch kulturelle Formung (Texte, Riten, Denkmäler) und institutionalisierte Kommunikation (Rezitation, Begehung, Betrachtung) wachgehalten werden. Wir nennen sie Erinnerungsfiguren. ${ }^{5}$

Die Verbindung mit dem Vergangenen schaffen Riten und Objekte, die als »kulturelle Objketivationen, ein kulturelles Gedächtnis ... stabilisieren, u. U. über Jahrtausende hinweg. ${ }^{6}$ Die Voraussetzung dazu ist aber das, was Assmann "Identitätskonkretheit« oder "Gruppenbezogenheit« nennt. Gerade an diesem Punkt wird die Betrachtung einer auf die Nation bezogenen kulturellen Identität oder der anderen Manifestation kollektiver Erinnerung des kommunikativen Gedächtnisses problematisch, sobald die schicksalhaften Ereignisse, die Brüche, die Katastrophen, die die Zusammengehörigkeit der Gruppe motivieren und auch psychologisch gewährleisten, Teil der Gegenwart sind.

Selbst eine neue Nation generiert ihre Identität nicht nach dem Prinzip der generatio ex nibilo, sie greift auf jene Texte, Symbole, Geschichtskonzepte und Methoden der Identitätsstiftung zurück, die ihr zur Verfügung stehen; sie vereinnahmt sie und liest sie neu, sie nimmt Bezug auf jenes, »was die Gesellschaft

4 Jan Assmann, »Kollektives Gedächtnis und kulturelle Identität«, in: Kultur und Gedächtnis, hrsg. von Jan Assmann und Tonio Hölscher, Frankfurt a. M. 1988, S. 9-19.

5 Ebda., S. 12.

6 Ebda. 
in jeder Epoche mit ihren gegenwärtigen Bezugsrahmen rekonstruieren kann. «7 Dadurch soll jene Unterdeterminiertheit neuer nationaler Strukturen verschleiert und kompensiert werden, die sich in der Diskontinuität, der Zerstörung tradierter Strukturen, der Willkürlichkeit, der Neuheit, der Unvereinbarkeit politischer und kultureller Geschichte zeigt. Die Vorstellung von Tradition als Produkt einer kollektiven, quasi unpersönlichen Regung der namenlosen Volksseele, die die »Polarität, in der dieses [Traditionszugehörige] letzte zum jeweils >Neuen< steht« nur fühlen, nicht aber artikulieren kann, lässt sich mit dem Szenario einer neuen Nation nicht in Einklang bringen. ${ }^{8}$

Die vorangestellte Skizzierung der Geschichte der iberischen Halbinsel im ausgehenden 15. und am Beginn des 16. Jahrhunderts ist nicht von ungefähr eine Darstellung der Verteilung und Umverteilung von Macht. Das Konzept der Macht stellt insofern das semantische Bindeglied zwischen dem Begriff der Autorität und der kulturellen Identität dar, als sich für meine Fragestellung die $\mathrm{Na}$ tion sowohl auf die Definition von Machtverhältnissen als auch auf die Schaffung von national konnotierten Identifikationsfiguren bzw. Autoritäten stützt. Diese Autoritäten müssen bestimmte Merkmale aufweisen, die »identifikatorische Besetztheit im positiven Sinne «, ${ }^{9}$ d. h. Nationalstolz und Zugehörigkeitsgefühl, fördern. Die Herausbildung dieser Fixpunkte aus dem Nährboden eines nationalen Traditionsbewusstseins in statu nascendi unterscheidet sich von der Entwicklung einer bruchlosen Tradition darin, dass ihre Objektivationen und Horizonte die Spuren ihres >Gesetzt $-<$ und >Gemacht-Seins« noch zeigen. Erfolgreich können diese nur dann sein, wenn sie den Nerv des Volkes treffen, wenn die Fixpunkte der Erinnerung in Einklang mit dem sind, was Miguel de Unamuno die »Intrahistoria« im Gegensatz zur »Historia« nennt. ${ }^{10}$ Damit meint er jenes psychologische Substrat des kollektiven Gedächtnisses, das die Identifikation von Volk und Geschichte über die Dynamik der »Historia«, also die Dynamik der Ereignisse und der Chronologie hinweg gewährleistet. Es fragt sich nun: Von wem können Objektivierungen und Fixpunkte der Erinnerung neu gesetzt, interpretiert, aufgezeigt werden? Wer hat das Recht, nationale Tradition zu serfinden und zu oktroyieren und wer erteilt es? Wer besitzt die Macht

7 Ebda., S. 13.

8 Martin Staehelin, "Zum Phänomen der Tradition in der Musikgeschichte des 15. und 16. Jahrhunderts«, in: Studien zur Tradition in der Musik. Kurt von Fischer zum 60. Geburtstag, hrsg. von Heinrich Eggebrecht und Max Lütolf, München 1973, S. 85.

9 J. Assmann, Kollektives Gedächtnis (wie Anm. 4), S. 13.

10 Siehe etwa Miguel de Unamuno, En torno al casticismo, ( $\left.{ }^{1} 1895\right)$, Madrid 1968; Manuel García Blanco, En torno a Unamuno, Madrid 1965, S. 310-317. 
über die nationale Tradition, über das nationale Selbstverständnis, über eine nationale Identität?

\section{Viel Lärm um wenig? Musiknotendruck in Spanien und Portugal}

Die Begriffe der Macht, der Machtbefugnis und der Reaktion auf Macht stellen auch die Kriterien dar, nach denen die Wahl meines Untersuchungsobjekts getroffen wurde. Nicht die gesamte musikalische Überlieferung steht dabei zur Debatte, sondern nur jene Art musikalischer Überlieferung, die auf die ausdrückliche Genehmigung durch die Machthaber angewiesen ist und sich an einen breiten Adressatenkreis anonymer Rezipienten wendet, zwei Eigenschaften, die im Fall von handschriftlicher Überlieferung nur in Ausnahmefällen nachgewiesen werden können, hingegen konstitutive Merkmale der Drucküberlieferung sind.

Diese Wahl stellt im iberischen Raum eine entscheidende Einschränkung dar, war dieser doch auf dem Gebiet des Druckes und speziell des Musikdruckes ein behäbiger und recht fauler Nachzügler. Die ersten Musikdrucke im engeren Sinne, also Drucke, deren Inhalt aus Musik bestand, waren 1535 eine Vihuelatabulatur in Valencia und 1540 eine Orgeltabulatur in Lissabon. ${ }^{11}$ Bis 1650 zählt man in Spanien 29 Musikdrucke, in Portugal erschien erst 1609 der zweite Musikdruck, knapp 70 Jahre nach dem ersten. Berücksichtigt man auch die Druckerzeugnisse, die sich mit Musik beschäftigen, ohne Musikalien im strengen Sinne zu sein - jene, die RISM als "Écrits imprimés concernant la musique umschreibt, - so erhöht sich die Zahl, wenn auch nicht nennenswert. ${ }^{12}$ In Jahren und Zahlen stellt sich die Druckproduktion in Spanien und Portugal, die von Musik handelt oder Musik enthält, ausgenommen die Choraldrucke, zwischen 1492 und 1650 folgendermaßen dar (siehe Tabelle 1).

Offensichtlich handelt es sich hierbei um ein überschaubares Gebiet. ${ }^{13}$ Es lassen sich viele Gründe für die spärliche Druckproduktion anführen. Papiermangel, ungenügende ökonomische Mittel und industrielle Infrastrukturen sowie ein unterentwickeltes Vertriebsnetz machten den Musikdruck wirtschaftlich

11 Luis Milán, Libro de misica de vibuela de mano. Intitulado el maestro, Valencia 1535 (RISM M 2724); Gonçalo de Vaena, Arte nouamente inuentada pera aprender a tanger, Lissabon 1540.

12 François Lesure, Écrits imprimés concernant la musique, 2 Bde., München 1971 (RISM, B.VI).

13 Siehe dazu Cristina Urchueguía, Die mehrstimmige Messe im "Goldenen Jahrhundert". Überlieferung und Repertoirebildung in Quellen aus Spanien und Portugal (ca. 1490-1630), Tutzing 2003 (Würzburger musikhistorische Beiträge, 25), S. 49-62. 
unattraktiv. Die harte und stark bürokratisierte Zensur durch die Inquisition stellte einen nicht zu vernachlässigenden Verunsicherungsfaktor dar.

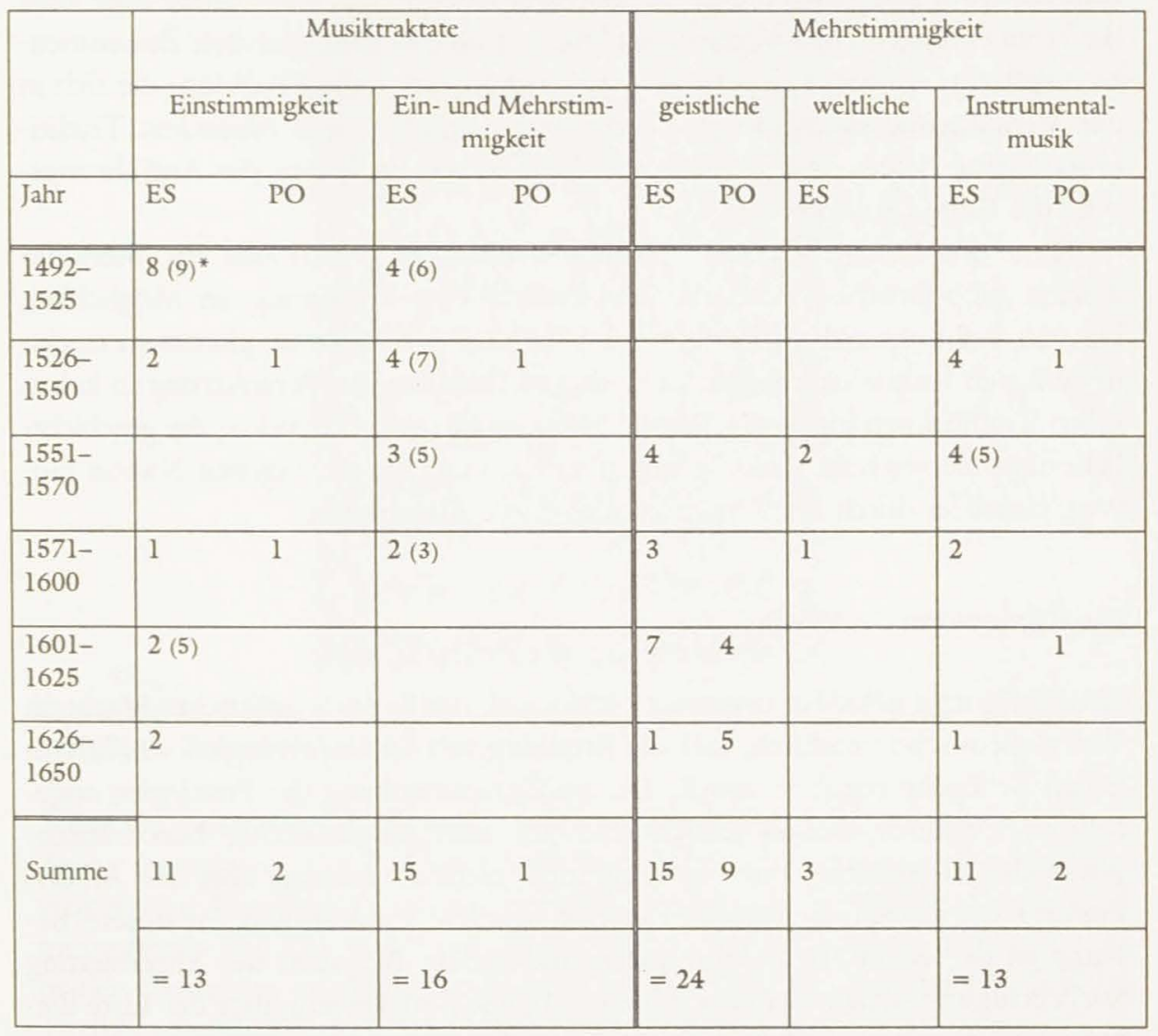

*In Klammern die Anzahl der Auflagen; ES=Spanien, PO=Portugal

Tabelle 1: Musikdruck in Spanien und Portugal zwischen 1492 und 1650

Wer Musik in den Druck geben wollte, wandte sich nach Lyon, Venedig, Rom oder sogar Prag. Jene Musikdrucke, die tatsächlich in Spanien erscheinen konnten, hatten alle erdenklichen Widerstände überstanden und genossen nicht selten die Unterstützung und finanzielle Förderung höchster Persönlichkeiten.

Wer also in einem spanischen Musikdruck einen Namen nennt und diesem Namen eine gewisse Beschwörungsmacht zuspricht - dies meine Arbeitshypothese - hat sich diesen Namen sehr genau überlegt, und er weiß, dass der Name 
willkommen und opportun, wenn nicht notwendig ist. Es lassen sich drei unterschiedliche Bereiche unterscheiden, für die Autoritäten von Belang sind. Diese spiegeln dann zum einen die kulturpolitische Gesamtlage, andererseits aber auch die Notwendigkeit einer allgemeinen kultur- und musikhistorischen Zusammenhangstiftung: erstens politische Macht, zweitens kulturelle Tradition, die sich in der Verankerung in philosophischen, mythologischen und biblischen Traditionssträngen äußert, und drittens musikalische Praxis, sei es die Aufführungsoder die Kompositionspraxis.

Diese drei Kategorien üben sehr unterschiedliche Funktionen aus. Stellt der Rekurs auf politische Machthaber nicht zuletzt eine Bedingung der Möglichkeit dar, die auf Rahmenbedingungen hinweist und den Rahmen gleichsam steckt, in dem sich Kultur artikulieren kann, so gewährleistet die Verankerung in kulturellen Traditionssträngen die Vergleichbarkeit mit dem Fremden, die geschichtliche und ideologische Anknüpfung über die Grenzen der eigenen Nation hinweg, entweder durch Identifikation oder durch Abgrenzung.

\section{Die Könige und die Musik}

Unverblümt, ja geradezu penetrant meldet sich der Bereich politischer Macht zu Wort, allein schon dadurch, dass die Erteilung von Druckprivilegien von öffentlichen Behörden reguliert wurde. Die im Zusammenhang der Privilegien angeführten Personen weisen jedoch eher auf rein pragmatische, bürokratischjuristische Zwänge hin. Ihre Nennung muss nicht als Aussage über den Autoritätswert der erwähnten Personen gelesen werden. Prädestiniert für unsere Belange ist der Raum, den Widmungen und andere Beigaben der Ehrerbietung zur Verfügung stellen. Dabei scheinen nicht alle Druckerzeugnisse der Liste diesen Raum in gleichem Maße zu beanspruchen.

Alle Traktate, die sich mit canto llano, mit Einstimmigkeit, beschäftigen, verzichten auf einen Widmungsträger von nationalem Rang, sie belassen sdie Kirche im Dorf . Schon der erste gedruckte Traktat, Marcos Domingo Duráns Lux Bella (1492) ist Petro Ximenio, Bischof der Diözese des Urhebers, gewidmet. ${ }^{14}$ Die Traktate zur Mehrstimmigkeit halten an dieser Praxis fest, solange sie sich äußerlich nicht von Traktaten zur Einstimmigkeit unterscheiden und keinen besonderen Anspruch erheben (siehe Abbildung 1).

14 Marcos Domingo Durán, Lux Bella ... Ars cantus plani composita brevissimo compendio, Sevilla 1492. 


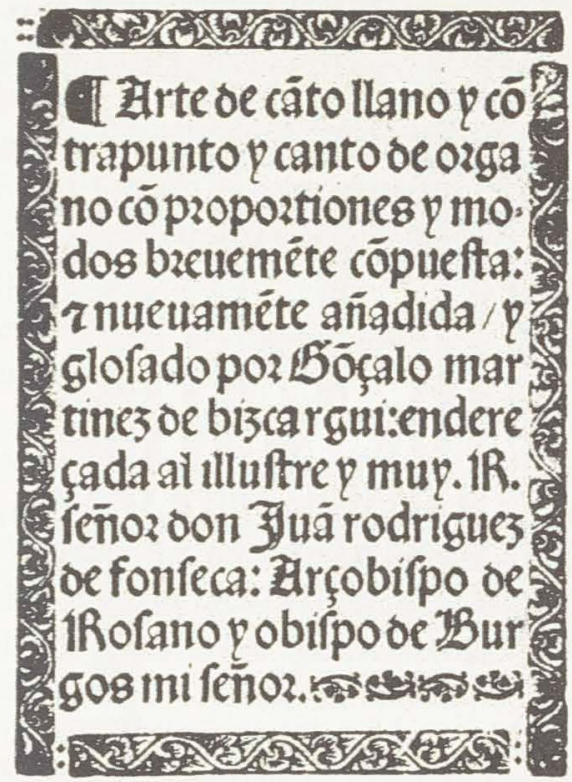

Abbildung 1: Martinez de Bizcargui, Arte de canto llano y contrapunto, 3. Fassung, 1. Auflage, Zaragoza 1538, Titelblatt

Selbst der erfolgreichste Traktat der Liste, Martínez de Bizcarguis Arte de canto llano y contrapunto, der zwischen 1508 und 1550 in drei stark voneinander abweichenden Fassungen zehnmal nachgedruckt worden ist, hält an dieser Widmungspraxis fest. Die erste Fassung erschien noch im Quartformat, die anderen beiden Fassungen verkleinerten auf Oktav. Bis auf die Schmuckbänder auf dem Titelblatt verzichtet der Druck auf jegliches Ornament. Die Widmungen - in der ersten Fassung an Pascual aus Burgos und ab der zweiten Fassung (1515) an Juan Rodríguez de Fonseca - erklären sich aus einem institutionellen Abhängigkeitsverhältnis: Beide werden nämlich als »mi señor « angesprochen. Sie waren nacheinander Bischöfe von Burgos, also die direkten Vorgesetzten von Martínez de Bizcargui. Inhalt und Zweck dieser Drucke bedürfen keiner Erklärung oder expliziten Kontextualisierung. Traktate zum Erlernen des ein- und mehrstimmigen Choralgesangs waren bekannte Textgattungen, die sich nur des neuen Mediums Druck zur besseren Verbreitung bedienten. Die Gruppe der Benutzer war eindeutig definiert, zum einen durch die Zweckbindung der Bücher, andererseits dadurch, dass die erforderliche Kompetenz, die Bücher zu benutzen, an eine bestimmte soziale Schicht, die der Kleriker, gebunden war. 


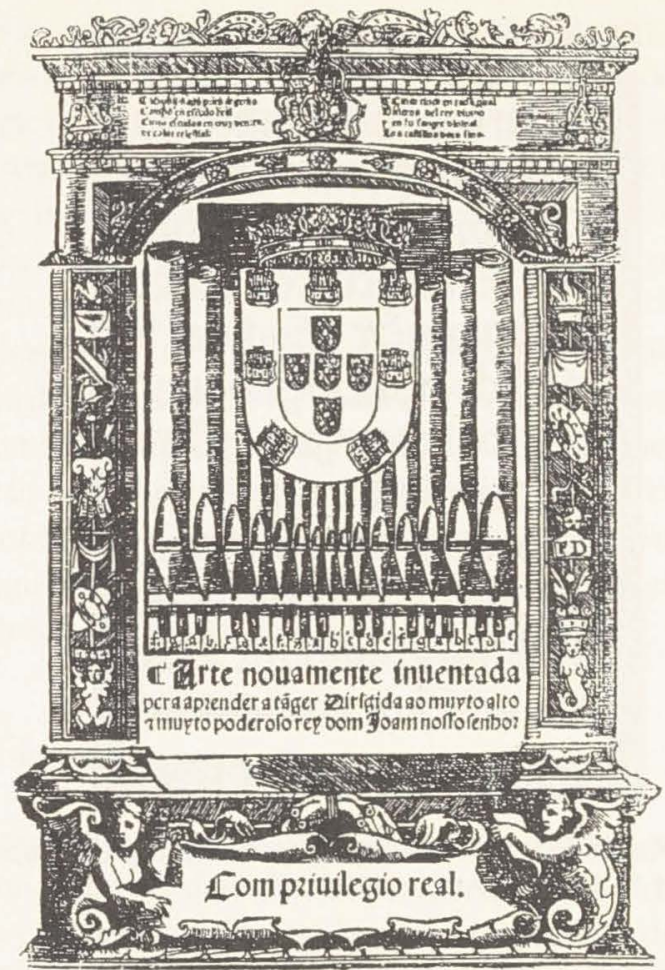

$\notin$

Abbildung 2: Gonçalo de Vaena, Arte nouamente inuentada, Lissabon 1540, Titelblatt

Anders verhält es sich bei jenen ersten Musikdrucken, deren Inhalt nicht traditionsgemäß ist. Darunter fallen die oben erwähnten Instrumentaldrucke von Luis Milán und Gonçalo de Vaena. ${ }^{15}$ Sie richteten sich an einen heterogenen, möglichst großen Adressatenkreis: an alle Musiker und Musikliebhaber oder an Menschen, die es werden wollten. Beiden Sammlungen ist der didaktische Habitus gemeinsam, sie liefern ausführliche Gebrauchsanleitungen zur Dekodierung des Notationssystems und zum autodidaktischen Erlernen des jeweiligen Instruments.

Bereits auf dem Titelblatt von Gonçalo de Vaenas Arte nouamente inuentada (siehe Abbildung 2) wird das Bestreben sichtbar, die Bedeutung des Werkes für die Nation hervorzuheben und auch den edlen Paten zu benennen. Die Wid-

15 Siehe Anm. 11. 
mung an den portugiesischen König Joăo III. erscheint auf dem Titelblatt, das königliche Wappen samt Beschreibungsgedicht nimmt den oberen Teil des Blattes ein, das königliche Privileg erscheint in einer Schmuckkassette unter dem Titel. In gewissem Sinne ist die Widmung an den portugiesischen König keine große Überraschung, war doch Gonçalo de Vaena damals knapp 40 Jahre lang im Dienste des portugiesischen Königs als Kammermusiker tätig gewesen. ${ }^{16}$ Auch hier eine Widmung an den Arbeitgeber?

Zwei weitere Drucke zeugen davon, dass das Arbeitsverhältnis nicht der einzige Grund gewesen ist, den portugiesischen König als Widmungsträger zu wählen. Er scheint aus noch ungeklärten Gründen eine einschlägige Adresse für jene Musiker dargestellt zu haben, die Neues wagten. So einleuchtend die Widmung von Gonçalo de Vaena ist, so rätselhaft ist die von Luis Milán. Dieser war 1535, beim Erscheinen seines Druckes in Valencia, als Musiker an der Hofkapelle von Herzog Ferdinand von Kalabrien und Germaine de Foix tätig. Dennoch widmet er seinen Druck ebenfalls dem portugiesischen König João III. und geizt auch nicht mit bildlichen Beigaben (siehe Abbildung $3 \mathrm{a}$ und $3 \mathrm{~b}$ ).

Luis Milán gehörte zum Typus jener aufstrebenden und ehrgeizigen Höflinge, die nicht nur genau wussten, was sich gehört, sondern auch, wie man es besser macht. Dieses Wissen fasste er, italienischem Vorbild folgend, in seinem Hofroman El Cortesano von 1561 zusammen. ${ }^{17}$ Einen Fauxpas gegenüber der Obrigkeit hätte sich Milán niemals erlaubt. Die Widmung seiner Vihuelatabulatur an den portugiesischen König wird noch bemerkenswerter, wenn man sie mit der Widmung derjenigen von El Cortesano vergleicht:

Libro Intitulado El Cortesano Dirigido Á la catolica Real Magestad del invictisimo don Felipe, por la gracia de dios rey de España, nuestro señor, etc. ${ }^{18}$

Das Buch, genannt Der Höfling, zugeeignet Seiner Katholischen königlichen Majestät, dem unbesiegten Don Felipe, von Gottes Gnaden König Spaniens, unserm Herrn, usw.

16 G. de Vaena, Arte (wie Anm. 11), fol. $5^{\mathrm{v}}$ : „De donde como yo considerasse ya llegado a sesenta años. Auiendo seruido casi quarenta a vuestra real alteza de musico de camara.« (»So dass ich erwog, als ich bereits sechzig geworden war und fast vierzig Jahre eurer königlichen Majestät als Kammermusiker gedient hatte.«).

17 Luis Milán, Libro Intitulado El Cortesano compuesto por D. Luis Milan, Valencia ${ }^{1} 1561,{ }^{2} 1565$, Neuausgabe Madrid 1874' (Colección de Libros españoles raros ó curiosos, 7).

18 Ebda., S. 1. 

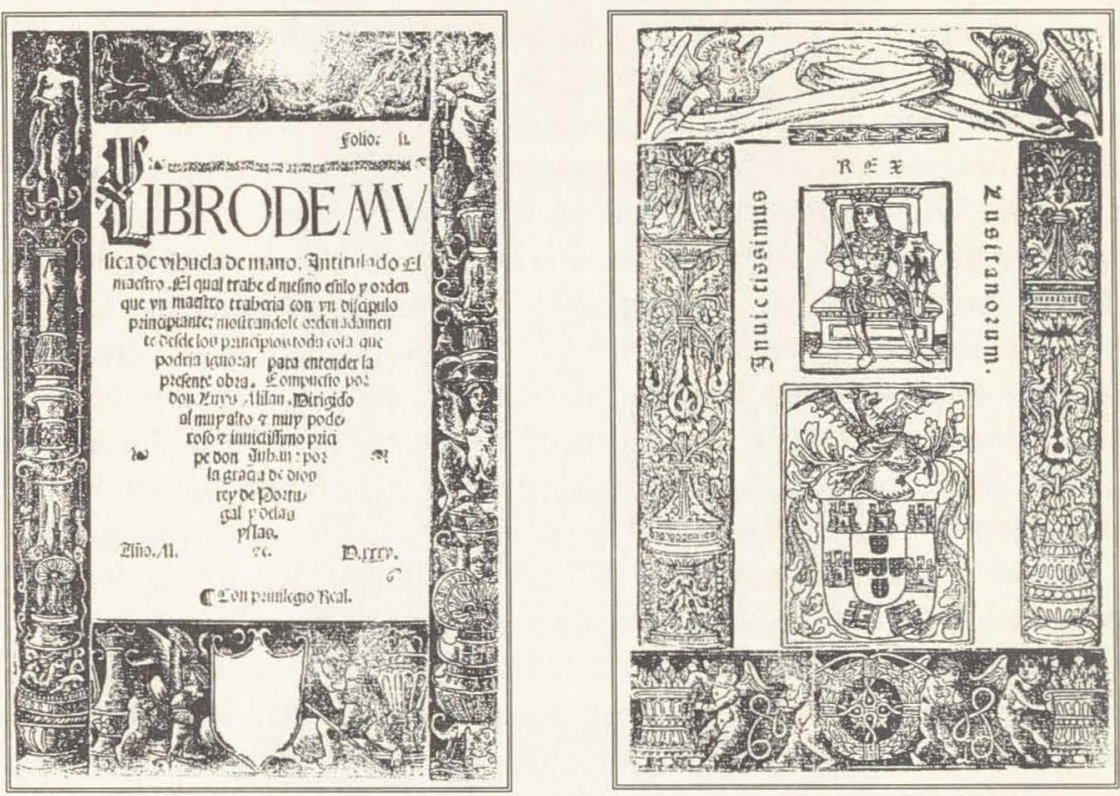

Abbildung 3a und 3b: Luis Milán, El Maestro, Valencia 1535, Titelblatt und fol. $2^{r}$

1549 wird ein drittes Musikbuch João III. gewidmet. Diesmal handelt es sich um die erste Fassung eines Musiktraktats, der nur aufgrund der herausragenden Stellung der zweiten Fassung - es handelt sich dabei um Juan Bermudos Declaración de instrumentos musicales von 1555 - in der musikhistoriographischen Versenkung verschwunden ist. Schon die Widmung an einen König zeugt davon, dass ein höherer Anspruch erhoben wird als bei allen früheren >Traktätlein<.

Bermudos El libro primero de la declaración de instrumentos musicales wird 1549 von Juan de León in Ossuna gedruckt und dem portugiesischen König zu Füßen gelegt. ${ }^{19}$ Man fragt sich nur, wieso spanische Autoren, wenn sie schon einen König zum Widmungsträger haben wollten, nicht den spanischen König dafür aussuchten. Karl V. erscheint nur indirekt in Luis de Narváez' Widmung der Seys libros del Delphin aus dem Jahr 1538: Sie richtet sich an Francisco de

19 Juan Bermudo, El libro primero de la declaracion de instrumentos, dirigido al clementissimimo y muy poderoso don Joan tercero deste nombre, rey de Portugal, Ossuna 1549. 
Covos, der dort unter anderem als Berater seiner Kaiserlichen Majestät erwähnt wird (siehe Abbildung 4).

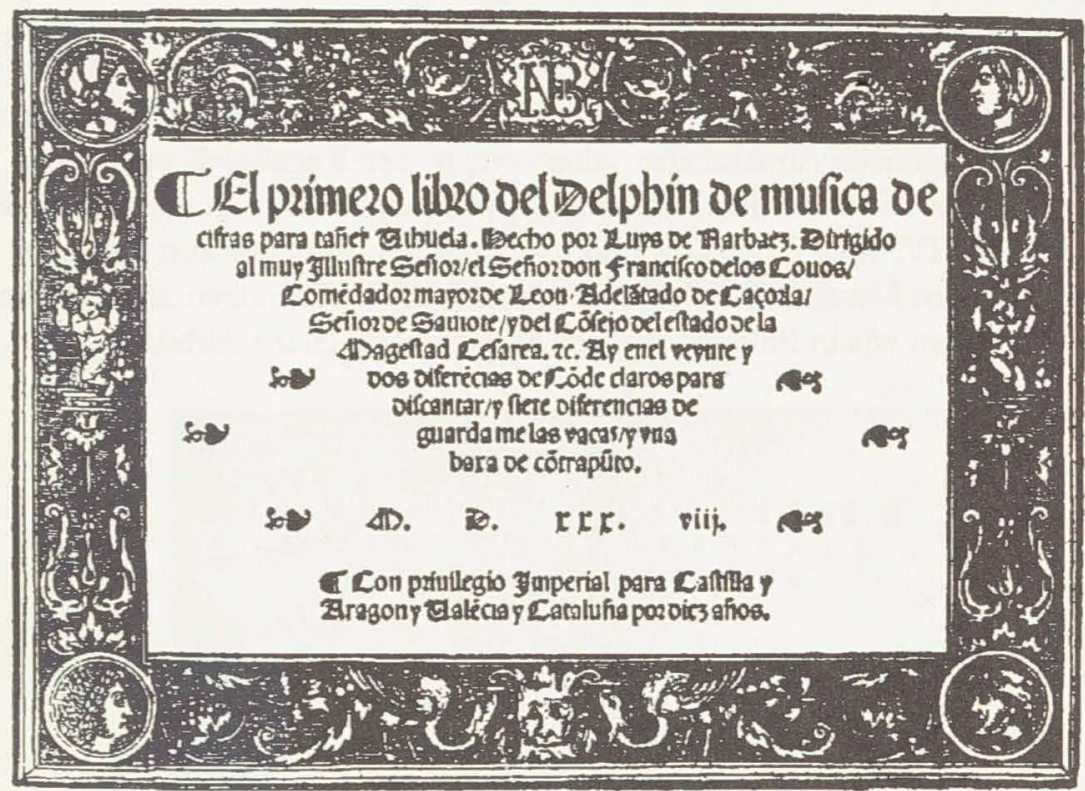

Abbildung 4: Luis de Narváez, Los seys libros del Delphin de música de cifras para tañer Vihuela, Valladolid 1538 (RISM N $66 / 1538^{22}$ ), Titelblatt

Ob sich die spanischen Musiker von einer Widmung an den portugiesischen König Privilegien oder Ehren erhofften, ist ungewiss, jedenfalls findet man im Inhaltsverzeichnis der Sammlung des portugiesischen Königs João IV. von 1649 die Tabulatur des Spaniers Milán, nicht aber die Orgeltabulatur des Portugiesen Vaena. ${ }^{20}$ Dagegen befand sich in der Sammlung des spanischen Königshauses kein einziges Exemplar eines Instrumentaldruckes, obschon dies am Beginn der Musikdruckproduktion die dominierende Publikationsform gewesen ist. Es ist auch keines aus höfischem Besitz nachgewiesen. Wenn es welche am Hof gab, dann gehörten sie zum Privatbesitz seiner Mitglieder und gingen nicht in die Hofsammlung über. Dass sich das einzige Exemplar der Orgeltabulatur

20 Limraria de Música de El-Rei D. Joāo IV. Estudo Musical, Histórico e Bibliográfico. Primeria parte do index da livraria de Música de El-Rei D. Joāo IV. Reproduçāo Facsimilada da Edifāo de 1649, mit Erläuterungen von Damiāo Peres hrsg. von Mário Sampayo Riberio, Lissabon 1967. Milán erscheint hier als Nr. 442. 
Vaenas heute im Königspalast zu Madrid befindet, könnte entweder reinen $\mathrm{Zu}$ fall oder die Ausnahme zu dieser Regel darstellen. ${ }^{21}$

Von ca. 1550 an scheint es für einen spanischen Musiker und Herausgeber nicht mehr möglich gewesen zu sein, die spanische Krone zu ignorieren. Bis zum Beginn des 18. Jahrhunderts wenden sich alle Musiker und Drucker mit ihren Widmungen an das spanische Königshaus, zuweilen werden hohe Beamte oder hohe kirchliche Amtsinhaber adressiert; in der Regel zielt man direkt auf die Spitze: bis 1556 auf den Regenten Prinz Philipp, dann an die Könige Philipp II., III., IV. und V. Analog und mit ähnlicher Emphase tun dies auch die portugiesischen Musiker: Nicht selten prangen die Widmungen auf monumentalen Titelseiten wie in Philippe Rogiers Messendruck (siehe Abbildung 5).

\section{Mifla}

P H I L I P P I R O G E R I I

A TR E B A T E N S I S S A C E L'LI. RECIIPHONAS CI M Y S C AE peritifsimi, \& xtatis fux Facile Principis.

A D P H I L I P P V M T E R T I.V. M H I S P A I AR V M RECE M

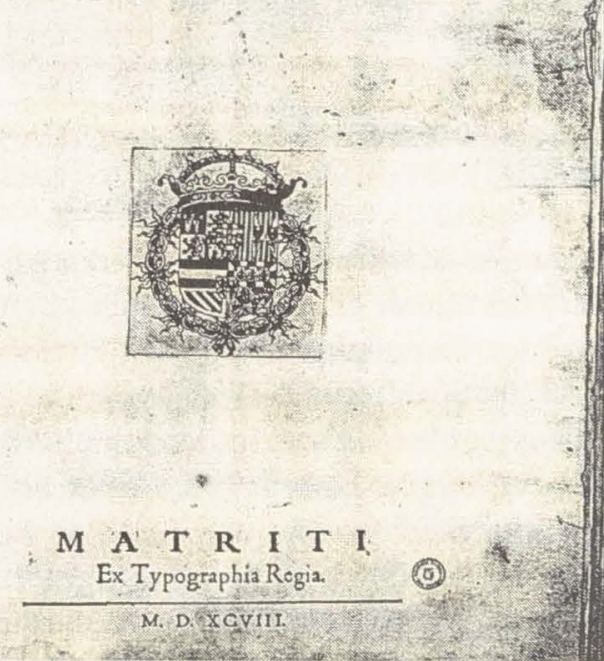

Abbildung 5: Philippe Rogier, Missæ Sex, Madrid 1598, Titelblatt

21 Sie befindet sich heute in Madrid im Palacio Real (E-Mp) unter der Signatur VIII/1816. 
Dieser schönen Regelmäßigkeit muss etwas Zwanghaftes innegewohnt haben. Sobald die Drucke außerhalb Spaniens produziert wurden, hatten spanische Herausgeber kein Bedürfnis nach pompösen Widmungen, wie man an der Sammlung Villancicos De diuersos Autores von 1556 erkennt (siehe Abbildung 6). ${ }^{22}$

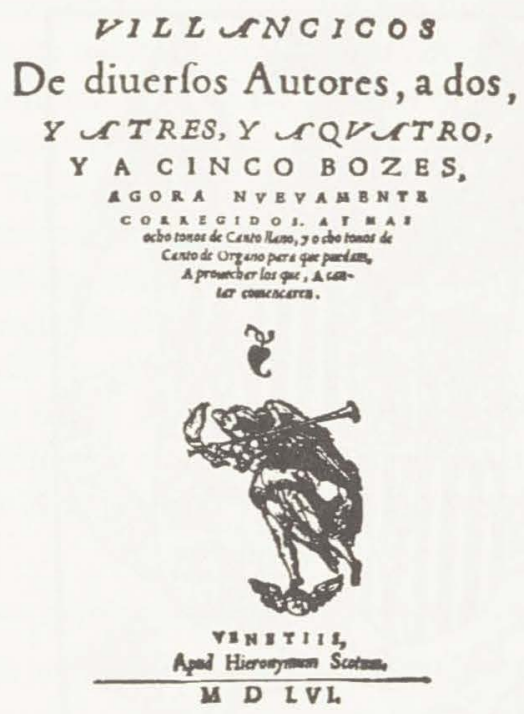

Abbildung 6: Villancicos De diuersos Autores, Venedig 1556, Titelblatt

Diese unter dem Beinamen Cancionero de Uppsala bekannte Sammlung weltlicher, mehrstimmiger Werke nimmt in Bezug auf die Funktionalisierung von Autoritäten dadurch einen paradigmatischen Stellenwert ein, dass sie beinahe die absolute Negation von Autorität und Autorschaft inszeniert. Wir finden auf dem Titelblatt einen einzigen Namen: Hieronymus Scotus, der als Drucker und wohl auch als Verleger verantwortlich zeichnet. Weder der Kompilator noch die Autoren von 53 der 54 Werke werden namentlich erwähnt. ${ }^{23}$ Nur ein einziges

22 Villancicos De diuerros Autores, a dos, $\Upsilon$ A TRES, $\Upsilon$ A QVATRO, $\Upsilon$ A CINCO BOZES, AGORA NVE-VAMENTE CORREGIDOS. AY MAS ocho tonos de Canto llano, y a ocho tonos de Canto de Organo, Venedig 1556 (RISM $1556^{30}$ ).

23 Die Literatur gibt an, dass drei Villancicos der Sammlung Matteo Flecha zugeschrieben sind. Diese Angabe kann ich nach Durchsicht des Faksimiles nicht bestätigen. 
Werk ist zugeschrieben: Nicolas Gomberts fünfstimmiger Villancico »Dezilde al cauallero«. Dieses Werk repräsentiert eine doppelte Ausnahme: Es ist das einzige Werk Gomberts in spanischer Sprache, und es ist das einzige Werk der Villancico-Sammlung, das zugeschrieben wurde, und zwar einem Ausländer, der unter ungeklärten Umständen von seinem Amt als maître des enfants und Hofkomponist Karls V. entlassen wurde.

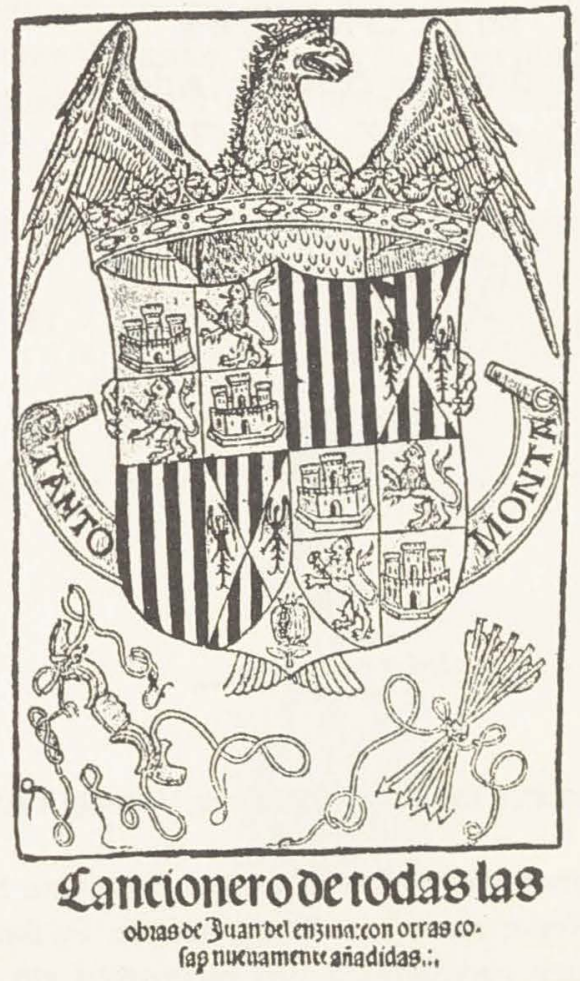

Abbildung 7: Cancionero de todas las obras de Juan del enzina: con otras cosas nueuamente añadidas, Zaragoza 1516, Titelblatt

Man könnte jetzt das Fazit ziehen, dass die sichtbare Darstellung nationaler $\mathrm{Zu}$ gehörigkeit und königlicher Patenschaft erst nach 1550, genauer gesagt erst mit der Regentschaft Philipps II. notwendig und erwünscht war. Damit lässt sich auch die Umorientierung Luis Miláns vom portugiesischen König 1535 zum spanischen König 1561 erklären. Diese Interpretation trägt aber einem pragmatischen Umstand nicht Rechnung, nämlich dem späten Beginn einer Produktion 
von Musikdrucken in Spanien. Wir sahen, dass während der Regierungszeit der Katholischen Könige ausschließlich Musiktraktate zum Erlernen einstimmigen und mehrstimmigen Gesangs entstanden. Aufgrund der Zweckbindung, der provinziellen Verbreitung und des auf Kirchenmusiker beschränkten Addressatenkreises war eine königliche Widmung unangemessen oder schlichtweg unnötig. Anspruchsvolle literarische Werke dagegen suchten bis zum Tod König Ferdinands 1516 die Nähe zum Königshaus (siehe Abbildung 7).

Die Bedeutung von Juan del Encina für die Entstehung einer Literatur in spanischer Sprache kann nicht überschätzt werden, ganz zu schweigen von seiner Leistung als Komponist. ${ }^{24}$ Neben der Kanonisierung bestimmter volkssprachlicher Gattungen wie Villancico, Romance und Canción, verfasste er die ersten dramatischen Texte in spanischer Sprache. Er bestellte die erste gedruckte 'Gesamtausgabe $<$ eines modernen spanischen Dichters, seine eigene, den Cancionero von 1496, die zu den frühesten in Europa zählt. Darin erschöpft sich aber die Liste seiner Errungenschaften noch nicht. Zusammen mit seinem Cancionero publizierte er 1496 die erste gedruckte Poetik der spanischen Sprache: die Arte de poesia castellana, in der er sein künstlerisches Selbstbewusstsein und sein Engagement für die Förderung einer Nationalliteratur zum Ausdruck bringt. Sein Cancionero und seine Arte de poesia weisen in der ersten Auflage von 1496 folgende Widmung auf:

A los muy poderosos y cristianíssimos príncipes don Hernando y doña Ysabel. ${ }^{25}$

Den sehr mächtigen und christlichsten Prinzen Don Fernando und Dойa Isabel.

Das Titelblatt der vermehrten Auflage des Cancionero von 1516 könnte, diesmal graphisch, keine deutlichere politische Aussage in diesem Sinne treffen (siehe Abbildung 7). Auf kleinstem Raum finden wir alle Symbole königlicher Macht versammelt: Königsadler, königliche Krone, die ein zusammengesetztes Wappenschild umspannt. Das Schild ist geviertet, wobei der untere Zwickel vom restlichen Teil abgetrennt wurde. Die unteren Felder erhielten die Form von kleinen Schildern, die im großen integriert sind. Zwei Felder, oben links und unten rechts, zeigen Burgen und aufspringende Löwen, die Wahrzeichen des Königreichs Kastilien mit León. Die gegenüberliegenden Felder sind wiederum zweigeteilt: Die eine Hälfte ist senkrecht fünfgeteilt, die andere hat denselben

24 Siehe dazu Juan del Encina, Poesía lírica y cancionero musical, hrsg. von Royston Oscar Jones und Carolyn R. Lee, Madrid 1975.

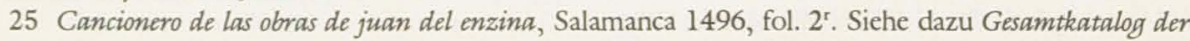
Wiegendrucke, hrsg. von der Deutschen Staatsbibliothek zu Berlin, Bd. 8, Stuttgart 1978, S. 34, Nr. 9301; Catálogo General de Incunables en Bibliotecas Españolas, Bd. 1, Madrid 1989, S. 354. 
Herold, erscheint jedoch schräg geviertet, um an den Seiten Raum für zwei Adler freizulassen - die Wappen des Königsreichs Aragon mit Katalonien. Im unteren Zwickel findet sich ein Granatapfel, das Wahrzeichen Granadas. Die beiden Worte auf dem Wappenspruch - »Tanto monta - wurden dem Motto der Katholischen Könige entnommen:

Tanto monta, monta tanto Isabel como Fernando.

Dieser Chiasmus bringt mich, wie jeden Übersetzer, in Verlegenheit, daher umschreibe ich sinngemäß: Isabella und Ferdinand sind in allem gleichberechtigte Herrscher. Die Gestaltung des Wappens als mise en abime und der Wappenspruch thematisieren den Widerspruch zwischen der Einheit und der Vielgliedrigkeit des Landes. Nur die persönliche Vereinigung der Herrscher miteinander stiftet den politischen Zusammenhalt der Königreiche. Die Platzierung der Embleme der beiden Monarchen verrät aber, wie brüchig der Zusammenhalt war: Die Pfeile für Isabella und das Joch für Ferdinand schweben unvermittelt, gewissermaßen in campo aperto unter dem Wappen.

An dieser Stelle lohnt der Seitenblick auf unser Wissen über die Kulturpolitik der Katholischen Könige, ihre Wertschätzung von Büchern bzw. von Buchdruck und von Bildung, ihr mäzenatisches Wirken zugunsten von Nationalkultur und -kunst. ${ }^{26}$ Wenn die Worte »Katholische Könige« fallen, denkt man in der Regel an die Wiedereinsetzung der Inquisition, an die Vertreibung der Juden, an christlichen Fundamentalismus, die Schlagwörter der Leyenda negra. Unbekannter sind jedoch Bestimmungen wie etwa folgende Pragmática acerca de los libros de molde, die "Pragmatik über die gedruckten Bücher" vom 8. Juli 1502:

E mandamos a los dichos libreros et imprimidores y mercaderes y factores que fagan y trayga[n] los dichos libros bien fechos et perfectos et bien corregidos y emendados y escritos de buena letra et tinta et buenas margenes y en buen papel: y no con titulos menguados: por manera que toda obras sea perfecta: y que en ella no pueda auer ni aya falta alguna so las dichas penas. ${ }^{27}$

Und wir befehlen besagten Buchhändlern und Druckern und Händlern und Herstellern, sie mögen besagte Bücher gut gemacht und perfekt herstellen und liefern und gut korrigiert und emendiert und mit guter Type und guter Tinte gemacht, mit großzügigen Seitenrändern und gutem Papier und nicht verkürztem Titel,

26 Ich berufe mich hierbei auf José García Oro, Los reyes y los libros. La politica libraria de la Corona en el Siglo de Oro (1475-1598), Madrid 1995.

27 Cristóbal Pérez Pastor, La Imprenta en Toledo. Descripción bibliográfica de las obras impresas en la Imperial Ciudad desde 1483 hasta nuestros dias, Madrid 1887, S. IXf. 
damit jedes Werk perfekt sei, auf dass es keine Fehler geben könne und gebe unter der Androhung besagter Strafen.

Die Gesetzgebung der Cortes von 1480 legte in seinem Paragraphen 97 die freie Einfuhr von Büchern fest. Manch heutiger Leser würde sich über diese Gesetzgebung freuen. Nicht nur die Vollständigkeit und Korrektheit des Textes wird gesetzlich gefördert, auch ein hoher Qualitätsstandard für die typographische, graphische und technische Gestaltung. Die zollfreie Einfuhr von Büchern stellt keine gesetzliche Floskel dar, an ihr wurde gegen den Protest der einheimischen Drucker festgehalten; wer das Geld hatte, konnte um 1500 jedes in Europa produzierte Buch bei ausländischen Agenten in Barcelona oder Alcalá de Henares erwerben.

Das Jahr 1492, von dem im Zusammenhang mit drei Ereignissen bereits die Rede war, steht auch für eine der entscheidenden kulturellen Errungenschaften der entstehenden Nation. Antonio de Nebrija, der 1473 nach langjährigem Studienaufenthalt in Italien nach Spanien zurückgekehrt war, um an der Universität zu Salamanca Latein zu lehren, veröffentlicht seine Grámatica de la lengua castellana und widmet sie

Ala mui alta et assí esclarecida princesa doña Isabel. la tercera deste nombre. Reina i Señora natural de España et las islas de nuestro mar. ${ }^{28}$

Der hohen und durchlauchten Prinzessin Doña Isabel, die dritter dieses Namens. Der natürlichen Königin und Herrin Spaniens und der Inseln unseres Meeres.

Im Vorwort stellt Nebrija eine Verbindung zwischen Sprache und Nation her, die den kulturellen Patriotismus des Verfassers, aber auch einer Generation von Intellektuellen prägt:

Cuando bien comigo pienso mui esclarecida Reina: i pongo delante los ojos el antigüedad de todas las cosas: que para nuestra recordación e memoria quedaron escriptas: una cosa hallo e saco por conclusión mui cierta: que siempre la lengua fue compańera del imperio: e de tal manera lo siguió: que junta mente començaron. crecieron. e florecieron. e después junta fue la caída de entrambos. ${ }^{29}$

Wenn ich für mich nachdenke, durchlauchtigste Königin, und mir das Alter aller Dinge vor Augen führe, die für unsere Erinnerung geschrieben wurden, gewinne ich dabei eine klare Erkenntnis, nämlich, dass die Sprache stets die Partnerin des Imperiums gewesen ist, dass sie ihm dergestalt folgte, dass sie zusammen begannen, wuchsen und erblühten und dass deren beider Fall gemeinsam erfolgte.

28 Antonio de Nebrija, Gramática de la lengua castellana, Salamanca 1492, fol. $2^{\text {r. }}$ Zu einer Übersicht über das Werk von Nebrija siehe Catálogo General de Incunables (wie Anm. 26), S. 7174.

29 Ebda., Vorwort. 
Die Liste jener Reiche, deren Geschichte nach besagtem Muster im Vorwort beschrieben wird, beginnt bei den Assyrern, Ägyptern und Juden und kulminiert im Römischen Reich. Diesen Exempla der Geschichte wird die Geschichte Spaniens parallel gesetzt. Der Beginn einer spanischen Geschichtsschreibung fällt mit der Entwicklung einer handhabbaren und vermittelbaren spanischen Sprache während der Herrschaft Alfons' X. des Weisen (1221-1284, König von Kastilien und León seit 1252) im 13. Jahrhundert zusammen. Die Befreiung von den Arabern 1492 führt daher zu keinem Neubeginn, sondern zur Beendigung eines unrechtmäßigen Zustandes, zur Wiederherstellung der wahren Struktur Spaniens. Das Verdienst der Katholischen Könige besteht nach Nebrija in Folgendem:

I assí creció hasta la monarchía e paz de que gozamos primera mente por la bondad e prouidencia diuina: después por la industria. trabajo e diligencia de vuestra real Majestad. En la fortuna e buena dicha de la cual los miembros e pedaços de España que estauan por muchas partes derramados: se reduxeron e aiuntaron en un cuerpo e unidad de reino. La forma e travazón del cual assí está ordenada que muchos siglos. iniuria e tiempos no la podrán romper ni desatar. ${ }^{30}$

Und so wuchsen die Monarchie und der Friede, die wir genießen, zunächst durch göttliche Güte und Vorsehung, dann durch die Wirtschaft, Arbeit und Tüchtigkeit Eurer königlichen Majestät. Im Glück und der Seligkeit, durch die die Stücke und Teile Spaniens, die vielerorts zerstreut waren, sich zu einem Körper und einer Einheit im Königreich zurückversetzten und vereinigten. Die Form und der Zusammenhalt dieses ist dergestalt geordnet, dass es viele Jahrhunderte, Schmach und Zeitläufte nicht zerstören und trennen können.

Nach so vielen Jahrhunderten des Kampfes war die Entwicklung jener »artes de la paz«, der »Künste des Friedens«, deren Voraussetzung die Sprache darstellt, dringlich. Humanistische Grundgedanken werden explizit in den Dienst der Politik gestellt. Nebrija ist nicht der einzige im Königreich, dem diese Gesinnung zu eigen war, auch alle weiteren wichtigen Gestalter und Akteure der Politik der Katholischen Könige lassen sich hier anführen: die Kardinäle Pedro González de Mendoza, Fray Hernando de Talavera, Fray Francisco Ximénez de Cisneros, der Inquisitor und Lehrer der Infanten Fray Diego de Deza. Alle absolvierten ihr Studium an der Universität Salamanca, als sie begann, sich humanistischem Gedankengut aufzuschließen.

Die Stärkung und Förderung der wichtigsten Grundvoraussetzungen einer nationalen Kultur- und Bildungspolitik gehören von Anfang an zu den Zielen der Katholischen Könige: die Einführung des Buchdrucks ca. 1470, die Reform

30 A. de Nebrija, Gramática (wie Anm. 29), Vorwort. 
des Schulwesens und der Universitäten sowie die Gründung neuer Universitäten, die Bevorzugung von Gelehrten bei der Besetzung verantwortungsvoller, kirchlicher Ämter, die Förderung einzelner Gelehrter bei der Veröffentlichung literarischer und wissenschaftlicher Arbeiten.

Der Buchdruck wurde dadurch gefördert, dass in Italien ansässigen deutschen Druckern Steuerfreiheit in den Königreichen Spaniens versprochen wurde. Die Könige bedienten sich des Druckes zunächst als Mittel für die Anwerbung von Spenden zur Finanzierung ihres Krieges gegen die Araber, dann aber auch als Mittel der Selbstdarstellung und der Konsolidierung und Vermittlung ihres Machtanspruchs: Von 1484 an werden die Ordenanzas Reales, die Königliche Gesetzgebung, im Druck verbreitet. Das »felix matrimonium« erscheint dort in der Verkörperung der Könige von Gottes Gnaden, als Herrscher über

castilla de leon de arago[n] de cecilia de toledo de vale[n]cia de galizia de mallorcas de seuilla de cerdeña de cordoua de corcega de murcia de jahe[n] delos algarbes de algezira de gibraltar yde y condesa de barcelona señores / de bizcaya de y de molina duq[ue]s de atenas y de neopatria. ${ }^{31}$

Kastilien von Leon und Aragonien, von Sizilien und Toledo, von Valencia und Galizien und Mallorca, von Sevilla und Sardinien und Cordoba, von Korsika von Murcia, von Jaen, von der Algarve und Algeciras und Gibraltar, und Gräfin von Barcelona, Herren von Vizcaya und Molina, Herzöge von Athen und den Neuen Ländern.

Auch wenn sie stets auf die Zustimmung der jeweiligen Cortes von Kastilien, Aragón, Katalonien usw. angewiesen waren, stellen sie sich dar, als wären nur sie der alleinige Garant der Rechtsprechung. Dieses Ansinnen bleibt im Politischen ein symbolisches, gelingt jedoch nachhaltig im Kulturellen. Sie stehen bei einer nationalen Renaissance humanistischer Prägung Pate, die alle Bereiche des Wissens umschließt: 1490 erscheint Alfonso Fernández de Palencias Universal vocabulario en latín y en romance, 1492 Nebrijas Gramática, ca. 1492 sein lateinisch-spanisches Wörterbuch, ca. 1495 das spanisch-lateinische Pendant, ${ }^{32} 1499$ Rodrigo de Santaellas Vocabularium Ecclesiasticum, ein zweisprachiges lateinischspanisches Wörterbuch der kirchlichen und theologischen Terminologie, dediziert: »A la serenissima et christianissima princesa doña Ysabel ${ }^{33}$

Die Fragilität dieses Zusammenhalts wird spürbar, wenn König und Königin ihre tatsächlichen politischen und legislativen Pflichten zu erfüllen haben. In

31 Díaz de Montalvo, Ordenanzas Reales, Huete 1485.

32 Antonio de Nebrija, Dictionario latino-hispanicum, Salamanca 1492; ders., Dictionarium hispanolatinum, Salamanca ca. 1495.

33 Rodrigo Fernández de Santaella, Vocabularium Ecclesiasticum, Sevilla 1499, fol. 1r. 
der regionalen Gesetzgebung erweist sich der nationale Machtanspruch als Produkt der Juxtaposition unabhängiger, verbriefter Befugnisse der einzelnen Individuen dieses »felix matrimonium«. Der Wunsch nach nationaler Einheit ließ sich aber selbst dort nicht gänzlich unterdrücken, wie wir an den Fueros, den Regionalgesetzen für Valencia, 1493 sehen können (siehe Abbildung 8). ${ }^{34}$

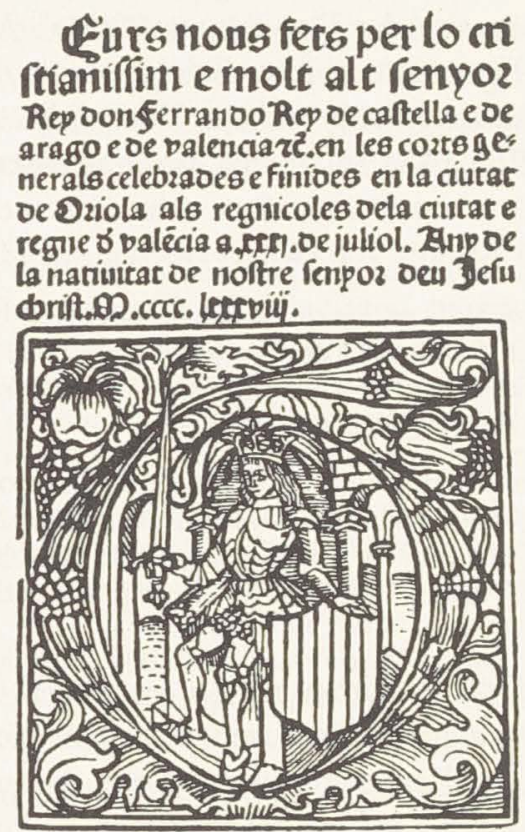

Abbildung 8: Furs de les Corts de Oriola, Valencia 1493

Der Titel dieser Regionalgesetze für Valencia lautet: »Neue Gesetze, die von dem christlichsten und hohen König Don Ferrando, König von Kastilien und Aragón, von Valencia ...« Der Text ist auf Valenzianisch verfasst, die Erwähnung von Kastilien beweist aber die Ambivalenz, in der die im Entstehen befindliche Nation und ihre Teile lebten. Die politische Spannung blieb bis zur Herrschaft Philipps II. ungelöst, die Gemüter der Regionen leicht entflammbar. Die Katholischen Könige wussten die allgemeine humanistische Aufbruch-

34 Siehe Konrad Haebler, Typographie ibérique du quinzième siècle. Reproduction en facsimile de tous les caractères typographiques employés en Espagne et en Portugal jusqu'à l'année 1500, Den Haag und Leipzig 1901/02, Nr. 127. 
stimmung in ganz Europa für sich auszunutzen. Die Verbreitungsmethode des Drucks und die richtigen Leute standen ebenfalls zur Verfügung. Der Erfolg der königlich geförderten Kanonisierungsmaßnahmen im kulturellen Leben war durchschlagend: Alle hier erwähnten Werke behielten den Status von Standardwerken bis ins 18. Jahrhundert. Dass spanische Buchdrucker bis 1535 nicht in der Lage waren, Musik zu produzieren, ist unser Pech.

Eines darf man aber bei aller Hochachtung nicht vergessen: Die inneren Widerstände im Lande waren zu groß, um die Konsolidierung einer wahrhaftig zentralisierten und absoluten Herrschaft zu erreichen. Den Teilerfolgen in der Innen- und Außenpolitik, in der Kultur- und Kirchenpolitik wurden der soziale Frieden und die wirtschaftliche Entwicklung geopfert. »Yet, in spite of this, a feeling of national euphoria and a sense of boundless optimism filled the Spain of the Catholic Monarchs. How would this spirit respond to the inexperienced rule of an alien prince? « ${ }^{35}$ fragt der Hispanist John Lynch. Die Antwort der Musiker und Musikdrucker lautet: gar nicht. Die Antwort der Bevölkerung, der Regionalregierungen und der Aristokratie lautet: Widerstand und Revolution.

Karl V. erreicht am 18. September 1517 Spanien und kündigt dem Regenten Kardinal Ximenez de Cisneros, der nach Ferdinands Tod 1516 die Regierung übernommen hatte. Drei Jahre dauert es, bis Karl die einzelnen Cortes von Kastilien, Aragonien und Barcelona dazu bewegt, ihn als König anzuerkennen. Im Gegenzug gab er Forderungen wie etwa dem Zwang, Spanisch zu lernen, nach. Es sei daran erinnert, dass die rechtmäßige Königin, Johanna die Wahnsinnige, erst 1555 starb. Viele Cortes bevorzugten den Bruder Karls V., Ferdinand, der in Spanien aufgewachsen war. Sie misstrauten einem König, der keinen biographischen Bezug zu Spanien hatte, und wünschten sich einen shauptberuflichen spanischen König. 1519 revoltierte die Bevölkerung in Valencia und Mallorca in der so genannten Guerra de Germanias gegen Karl und gegen die Aristokratie. Kaum hatte er im Mai 1520 das Land verlassen, um die Kaiserkrone entgegenzunehmen, erhoben sich die kastilischen Städte mit Unterstützung der Aristokratie in der Guerra der Comuneros gegen die ,Fremdherrschaft، durch einen Burgunder. Die Revolte endete im Oktober 1521 mit der Kapitulation Toledos.

Karl V. vermochte die aufgebrachten spanischen Cortes und Aristokraten nur dadurch zu beschwichtigen, dass er an der föderalistischen Struktur des Landes festhielt und nach und nach den Spaniern Zugang zu hohen Ämtern gewährte.

35 John Lynch, Spain under the Habsburgs, Bd. 1: Empire and Absolutism, 1516-1598, New York 1964, S. 34. 
Vizekönige vertraten ihn in den Cortes von Kastilien, Aragonien, Valencia, Sizilien usw., er selbst war nur mittelbar präsent und ansprechbar. Sollte es der Wahrheit entsprechen, dass Cristóbal de Morales mit seinem Ansinnen scheiterte, Karl als Widmungsträger seines ersten Messenbuchs zu gewinnen, so ist die kulturelle Unsichtbarkeit Karls V. sogar seinem Desinteresse zuzuschreiben. ${ }^{36}$

Erst Philipp II. vermag den nationalisierenden Geist der Katholischen Könige zu verkörpern und die unbestrittene Anerkennung durch die spanischen Regionen zu erhalten. Er konstituiert sich im wörtlichen Sinne als zentraler und absoluter Bezugspunkt nationaler Identifikation, die Schwächung der tradierten föderalen Struktur wird bei der zentralisierten Neuordnung Spaniens in Kauf genommen. Die Widmung als Mittel, königliche Präsenz im Kulturleben zu zeigen, wurde allem Anschein nach von der Krone, d. h. von Philipp II. bewusst Brachialgewalt soll hier nicht ausgeschlossen sein - durchgesetzt. Maßnahmen wie die Zentralisierung der Zensur und die Kanalisierung des Vertriebsnetzes der Choraldrucke durch das Kloster San Lorenzo del Escorial trugen wohl nicht in unerheblichem Maße dazu bei. Zeichnete sich das kulturelle Interesse der Katholischen Könige durch humanistische Züge, ihr mäzenatisches Wirken durch eine direkte und persönliche Anteilnahme aus, so lässt sich zu den kulturellen Interessen Philipps II. wenig sagen: Es sind Zensur und Inquisition, die die Inhalte regulieren. Nicht einmal vor dem Nationaldichter der Katholischen Könige macht die Inquisition halt: 1583 wird eine Egloga trobada por Juan del Encina von Kardinal Quiroga indiziert und aus dem Verkehr gezogen. ${ }^{37}$

\section{Wie die Musik spanisch wurde}

Die Widmung ist kein spezifisch musikalisches Element, sie bettet die Musikdrucke vielmehr in einen gesamtkulturellen Raum ein. Das musikhistoriographische und musikästhetische Denken manifestiert sich diskreter, doch zeigt sich auch hier die Tendenz zu Nationalismus und Patriotismus. Unumgänglich scheint es gewesen zu sein, explizit zu betonen, dass Spanien und Portugal von jeher als Länder bekannt sind, in denen die Musik besonders geschätzt wurde. Eine entsprechende Wendung fehlt in kaum einem Druck. Diese Behauptung beweisen die Autoren indirekt, indem sie die konventionalisierten Musik-My-

36 Gemeint ist Cristóbal de Morales, Missarum liber primus, Rom 1544 (RISM M 3580). Ich danke Dr. Klaus Pietschmann für den freundlichen Hinweis auf diesen Zusammenhang.

37 Egloga nuevamente trobada por Juan del Encina: en la qual se instroducen dos enamorados Pldcido y Victoriano, Toledo 1553; siehe dazu C. P. Pastor, La Imprenta (wie Anm. 28), S. 106, Nr. 266. 
thologeme bzw. Entstehungsmythen - seien es biblische, philosophische oder mythologische - aufrufen und für ihre Zwecke vereinnahmen (siehe Abbildung 9).

Luis Milán beruft sich in seinem Maestro von1535 auf Orpheus, eine nahe liegende Wahl. Hier sehen wir ihn in einem Locus amœenus, umgeben von Tieren, er spielt aber nicht die Lyra, sondern zweifelsohne das spanischste aller Instrumente, die Vihuela. Der umgebende Text, ein Gedicht, lautet:

El grande Orpheo / primero iuentor. / Por quienla vihuela paresce enel mundo. / Si el fue primero / no fue sin segundo. / Pues dios es de todos de todo hazedor.

Der große Orpheus, der erste Erfinder, / durch den die Vihuela in die Welt kam, / wenn er der erste war, war er nicht ohne zweiten, / denn Gott ist von allen, von allem der Schöpfer.

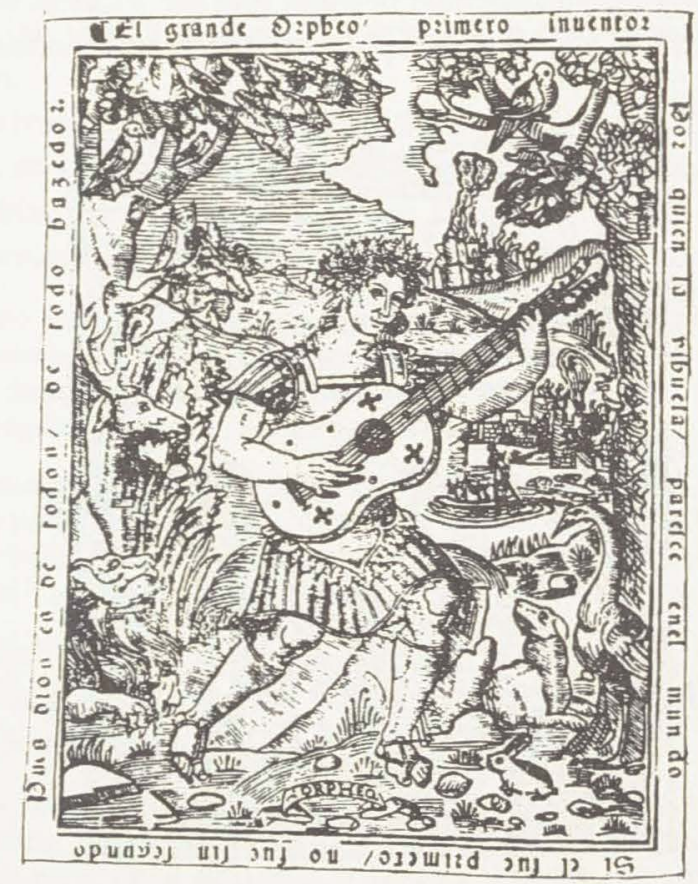

Abbildung 9: Luis Milán, El Maestro, Valencia 1535, fol. $3^{r}$

Mit einem Handgriff wird die Erfindung der Musik eine spanische und sie wird zudem christlich relativiert. Milán, der perfekte Höfling, der den italienischen Standard an die spanischen Höfe bringen wollte, irrt sich hier sicher nicht aus Unwissenheit, seine Umwidmung des Orpheus-Mythos ist keineswegs ein 
Überlieferungsfehler oder ein Versehen. In El Cortesano weiß er sich sehr wohl der überlieferten Ikonographie zu bedienen.

Wenn etwa Apoll singt, bedient er sich der »cítara«, der Zither, die Vihuela ist dem höfischen Alltagsgeschehen vorenthalten:

$D[o n a]$. Nos pot dir per vos aquel cantar que diu: Que no puede ser, seńor bachiller, que no puede ser ... Don Luis Milan tomó una vihuela, que esta señora le dió para que cantase este diálogo de amores. ${ }^{38}$

Dame: Könnt Ihr uns den Gesang vortragen, der sagt: Es kann nicht sein, Herr Bakkalaureus, es kann nicht sein ... Don Luis Milán griff zur Vihuela, die ihm diese Dame gegeben hatte, um diesen Liebesdialog zu singen.

Dass die Instrumente der Mythologie und der höfischen Alltagswelt unterschiedlich sind, war Milán sicherlich bewusst und die Vihuela war graphisch wie episch ein Bestandteil der Ikonographie höfischer Inszenierung (siehe Abbildung 10$):{ }^{39}$

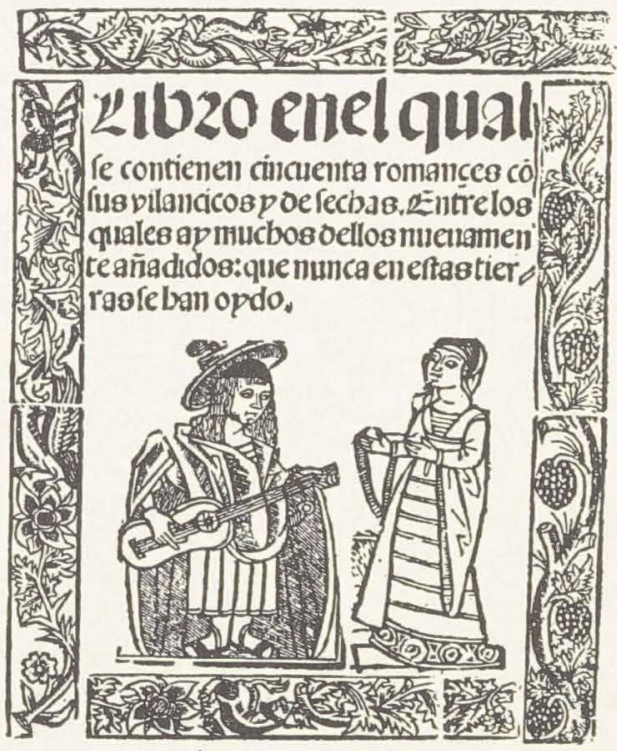

Abbildung 10: Libro en el qual se contienen cincuenta romances, o. O., ca. 1550

38 L. Milán, Libro Intitulado El Cortesano (wie Anm. 17), S. 454f.; S. 434: »Entró [Apolo] en esta fiesta con la ninfa Syringa, que tan dulcemente cantaba, como él con la cítara tañía.» („Er betrat das Fest mir der Nymphe Syrinx, die so süß sang, wie er mit der Zither spielte.«)

39 Siehe dazu Antonio Rodríguez-Moñino, Manual Bibliográfico de Cancioneros y Romanceros, Bd. 1: Impresos durante el Siglo XVI, Madrid 1973, S. 169-171, Nr. 28. 
Besonders elegant ist dieser Holzschnitt wahrhaftig nicht. Er sieht aus wie ein Modell aus einem graphischen Setzkasten, das man beliebig austauschen, kombinieren und verwenden kann. Die Szene ist einem konventionalisierten Repertoire entnommen.

Miguel de Fuenllanas Tabulatur von 1554 heißt auch Orphénica lyra, dies sei nur nebenbei erwähnt. Neben Orpheus begegnet uns eine große Schar an Figuren: Pythagoras, Boethius, Platon, Aristoteles, Martial, Petrarca, Kain und Abel, Alkibiades usw. Diese Namen sind nur selten inhaltlich notwendig. Nur in den Traktaten von Juan Bermudo und Francisco de Salinas findet eine fachliche Auseinandersetzung mit Musiktheoretikern und Philosophen statt. ${ }^{40}$ In allen Instrumentalwerken geht es den Autoren lediglich um den Beweis ihres Wissens und darum, sich entweder in die Fußstapfen der Zitierten zu begeben - nicht umsonst heißen die Werke Parnasso, Orphénica lyra oder Silva de Sirena ${ }^{41}$ - oder sie zu überbieten.

In komprimierter Form lassen sich viele Strategien des Umgangs mit den mythologischen und historischen Autoritäten im Vorwort von Vaenas Orgeltabulatur finden. Nach der Vorstellung seiner Person behandelt er die Bedeutung der Musik in Portugal und die Bedeutung Portugals für die Musik:

Visto lo mesmo que a todos es muy notorio. s. en estos vuestros muy famosos reynos y prouincias de Portugal/generalmente la musica ser estimada:sintida \& co[n]certada: tanto a la dul çura de su melodia quanto a la parte muy sotil de su theorica/auentajada mas $q\left[\right.$ ue] en otra parte del mundo, ${ }^{42}$

Man habe bemerkt, was allen offensichtlich ist, nämlich, dass in Ihren [des Königs] Reichen und Provinzen von Portugal in der Regel die Musik sehr geschätzt und ausgeübt wird, dass sie in Bezug auf die Süße der Melodie und den subtileren Bereich der Theorie entwickelter sei als in allen anderen Teilen Erde.

Da die Musik darüber hinaus im Einklang mit der Seele ist, nahm sich Vaena vor, einen Traktat zu schreiben, der weniger subtil, also theoretisch, denn nützlich sein möge. Schwierig sei die Materie, behauptet Vaena:

Aviendo visto enella [la música] en su forma ser semejante muy conforme a la forma de nuestra alma. ... Propuse de inuentar para con menos trabajo se alcançar mayor parte de la su pratica y theorica: esta arte no tanto sotil quanto prouechosa: sabiendo con quanto estudio se toca la gran su tileza o armonia de

40 J. Bermudo, Declaración (wie Anm. 1); Francisco de Salinas, De musica libri septem, Salamanca ${ }^{1} 1577$ und ${ }^{2} 1592$.

41 Esteban Daça, Libro de Música en Cifras para Vibuela intitulado El Parnasso, Valladolid 1576 (RISM DD 1274 / 1576 $)$; Enríquez de Valderrábano, Libro de Música de Vihuela, intitulado Silva de Sirenas, Valladolid 1547 (RISM V $32 / 1547^{25}$ ).

42 G. de Vaena, Arte (wie Anm. 11), fol. $5^{\mathrm{v}}$. 
las species que la musica contiene verdaderamente. Cuyo pro pio fundamento Aristotil no alcanço. Pitagoras ignoro. Alguno de los philosophos no escriuio. ${ }^{43}$

$\mathrm{Da}$ ich in ihr [der Musik] gesehen hatte, sie sei der Form unserer Seele ähnlich und sehr im Einklang mit ihr ... schlug ich vor, um mit weniger Arbeit den größten Teil der Theorie und Paxis zu erlernen, diese Kunst zu erfinden, die weniger subtil denn nützlich sein möge: ... wissend, wieviel Fleiß notwendig ist, um die Feinheit oder Harmonie der Spezies, die die Musik wahrhaftig enthält, zu berühren. Dessen Fundament von Aristoteles nicht erreicht wurde, von Pythagoras ignoriert, von einigen der Philosophen nicht geschrieben wurde.

Oder anders formuliert, da die großen Philosophen versagt haben, war seine Schule notwendig:

Assi mismo q[ue] puedan ver y aprender obras de grandes componedores. s. Oquegue[n]. Alixandre. Jusquin. Peñalosa: y dotros muchos: aquellos que nunca fueron enseñados. ${ }^{44}$

Darüber hinaus, damit diejenigen, die nie belehrt wurden, die Werke der großen Komponisten wie Ockeghem, Alexander [Agricola], Josquin, Peñalosa und vieler anderer sehen und lernen können.

Nachdem er seine Kenntnis der Theorie unter Beweis gestellt hat, setzt er sich über den Ballast der Geschichte hinweg, um die Musik selbst zum Lehrer zu erheben. Er schlägt die Brücke von der Theorie zur Praxis, von der Konvention zur Lebenswelt. Was er aber nicht vorzuhaben scheint, ist eine Überleitung von der Geschichte in die Gegenwart: Ockeghem, Josquin und Agricola waren 1540 lange tot, auch Peñalosa starb 1527.

Seine Aufzählung von Komponisten klingt nur auf den ersten Blick vertraut. Sie beginnt wie jede Auflistung der Zeit, die etwas auf sich hält, gipfelt jedoch in einer Überraschung: Francisco de Peñalosa. Im Kontext dieser Aufzählung gelingt es Vaena, den spanischen Autor an der Autorität seiner berühmteren Kollegen teilhaftig werden zu lassen. Vaena kanzelt die Philosophen mit derselben Vehemenz ab, mit der er die Musiker glorifiziert, wobei er die Gelegenheit wahrnimmt, einen Spanier in die Galerie der Größten mit einzuführen. Bleibt die Philosophenschelte floskelhaft, so wird die Auseinandersetzung mit der Praxis angesichts des Inhalts seines Druckes umso glaubhafter. Alle Musiker der obigen Liste sind mindestens mit einem Werk vertreten. ${ }^{45}$

43 Ebda.

44 Ebda.

45 Zum Inhalt des Druckes und zur Diskussion der Zuschreibungspraxis siehe Cristina Urchueguía, »Wahr oder falsch? Was bedeuten die Zuschreibungen in Gonçalo de Vaenas >Arte nouamente in-uentadar (1540)? «, in: Quellenstudium und musikalische Analyse. Festschrift Martin Just 
Am handschriftlich überlieferten Repertoire kann man sehen, dass sich die drei ausländischen Autoren, allen voran Josquin, großer Beliebheit erfreuten. Im gedruckten Repertoire wird vor allem die Vorbildfunktion Josquins offensichtlich. Peñalosa ist nur in der Tabulatur von Vaena vertreten, während wir Werke von Josquin in allen iberischen Tabulaturen finden, die Intavolierungen enthalten. Eine davon, Diego Pisadors Libro de Musica de Vibuela von 1552 - der erste Musikdruck, der dem Prinzen Philipp dediziert wurde, - enthält acht nahezu vollständige Messen von Josquin als Intavolierungen. Nachdem Pisador in der Einleitung dem Prinzen versichert hat: »sepa Vuestra alteza que este libro es el mas prouechosos que hasta agora se a compuesto (»wisse Eure Hoheit, dass dieses das nützlichste aller bisher erschienenen Bücher ist«), erklärt er die Vorliebe für Messen von Josquin folgendermaßen:

Puse tambien dos libros, en los quales se contiene[n] ochos missas de Iusquin porque los que hasta a qui han escripto no pusieron deste autor, sino muy pocas cosas escogiento dllos lo que les parescia yo quise poner ocho missas para el que quisiesse escogiesse conforme a su voluntad porque el musico fue tan bueno que no tiene cosa que desechar. ${ }^{46}$

Ich habe auch zwei Bücher eingefügt, in denen acht Messen von Josquin enthalten sind, weil diejenigen, die bisher schrieben, von diesem Autor nur weniges übernommen haben, und nur das nahmen, was ihnen recht erschien, ich wollte acht Messen nehmen, damit jeder nach eigenem Ermessen auswählt, weil er so ein guter Musiker gewesen ist, dass es nichts von ihm gibt, was man verwerfen müsste.

Zwar pochen alle Herausgeber auf Spaniens Vorliebe für Musik und Spaniens Kompetenz auf dem Gebiet, ein besonderes Interesse an der Heraushebung sspanischer Musik scheinen sie aber, mit Ausnahme von Gonçalo de Vaena, nicht zu haben.

Mit Bermudos Traktat Libro llamado declaracion de instrumentos musicales von 1555 veränderte sich diese Haltung gegenüber nationalen Komponisten grundlegend. Bermudos bemerkenswert moderner und praxisnaher Traktat kündigt schon im Titelblatt seine Wertschätzung spanischer Musiker und sein Engagement für sie an (siehe Abbildung 11):

zum 70. Geburtstag, hrsg. von Peter Niedermüller, Cristina Urchueguía und Oliver Wiener, Würzburg 2001, S. 47-82.

46 D. Pisador, Libro de Musica de Vihuela, Salamanca 1552 (RISM P2448 / 1552 ${ }^{35}$ ), Widmung an „Felipe II., Philippe principe de Espana nuestro Señor «, fol. Aiv und Aiir. 


\section{¿ेComiença el librollamadode

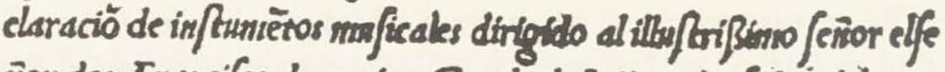

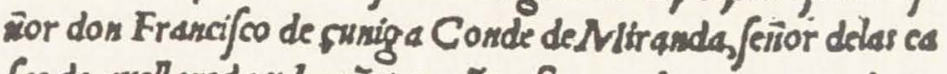 fas de avellaxeda y bafä erc.cöpmefto por el miny rexerendo pa dre fray Iuă Bermudo dela ordē delos meworesien el qual balls

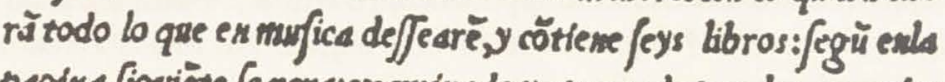 pagina figniète fe verasexaminado y apronado por los egreoflos muficos Bernardino de figueroa,y Cbrifrowal de morales. I 5 ss}

Abbildung 11: Juan Bermudo, Libro llamado declaracion de instrumentos musicales, Ossuna 1555, Titelblatt

Hier betont Bermudo, das Buch sei von Bernardino de Figeroa und von keinem Geringeren als Cristóbal de Morales geprüft worden. Letzterer meldet sich im Traktat sogar persönlich in einem 1550 datierten Brief zu Wort, in dem er im Ton überschwänglichen Lobes dazu aufruft:

Leed con auiso y cuydado este libro: hallareys en el todo lo que en composicion podeys deßear. Theorica engastada en practica, y la practica corrieße junctamente con la theorica: hasta ahora en nuestra España no auemos visto. ${ }^{45}$

Lest dieses Buch mit Aufmerksamkeit und Sorgfalt: Ihr findet darin alles, was ihr für die Komposition wünschen könntet. Dass dergestalt die Theorie in die Praxis eingebettet ist und die Praxis mit der Theorie Hand in Hand geht, haben wir in Spanien bisher noch nicht gesehen.

Bermudo versäumt es nicht, sich für diese Ehre gebührend zu bedanken. Er deklariert Morales gegenüber Gombert zum Sieger in einem imaginären Wettbewerb, in dem es um das Problem »mi contra fa" geht:

En obras de Gomberth hallareys fa contra mi muchas vezes: pero en minima. Quien mejor, a mi ver, ha preparado el sobredicho interualo defendido: es el excelente musico Christoual de morales en vna mißa de Requiem que hizo para el señor Conde de Vreña en el verso del introyto que dize Te decet, en la palabra Votum in hierusalem, y dila segun se sigue. ${ }^{46}$

In Werken von Gombert begegnet man $m i$ contra fa einige Male, aber als Minima. Wer aber, meines Erachtens, dieses verbotene Intervall am besten vorbereitet hat, ist der herausragende Musiker Cristóbal de Morales in seiner Requiem-

47 J. Bermudo, Declaración (wie Anm. 1), fol. $120^{\vee}$.

48 Ebda., fol. $139^{r}$. 
Messe, die er für den Herzog von Ureña komponierte, im Vers des Introitus bei den Worten Votum in Jerusalem, und er tat es folgendermaßen.

Es folgt ein Notenbeispiel. Die zitierte Komposition ist nur handschriftlich überliefert, sie ist ein Teil des Spätwerks von Morales und wurde womöglich sogar erst nach dem Brief, der im Traktat zitiert ist, komponiert. Bermudo ging es aber nicht nur um den Spanier Morales, sondern um die spanischen Komponisten im Allgemeinen. Einer seiner pädagogischen Ratschläge lautet:

Creed, que ningun hombre sabio puro practico puede dezir tanto por letras: quanto descubrira en la composicion. Los que tuuieren por particular exercicio, y contino estudio mirar con mucha atención obras de grandes musicos: sabran bien componer, y pues que en nuestra Espańa al presente los ay muchos y extremados: no aprouecharse el discipulo gran culpa sera suya. ${ }^{49}$

Glaubet mir, kein weiser Mann der Praxis kann so viel mit Buchstaben sagen, wie er in den Kompositionen entdeckt. Diejenigen, die sich besonders der fortwährenden und aufmerksamen Betrachtung der Werke großer Komponisten widmen, werden gut zu komponieren wissen, und da es in Spanien gegenwärtig viele und außerordentliche gibt, wird der Schüler selber schuld sein, wenn er die Gelegenheit nicht wahrnimmt.

Von hier an wird die Beteuerung der Exzellenz spanischer Musiker zum Topos. Dass der deutsche Gasparus Stoquerus, ein Schüler von Francisco de Salinas, der wahrscheinlich Kaspar Stocker hieß, in seinem Musiktraktat (ca. 15701580 ) sich auf diesen als »longè in utraque Musices parte praestantissima auctoritas $~^{50}$ (»in beiden Bereichen der Musik bei weitem hervorragendste Autorität «) beruft, lässt sich geradezu als Umkehrung des Status quo vor Bermudos Traktat bewerten: Ein Spanier wird zum Vorbild des Ausländers.

\section{Zu sich selbst finden, über Umwege}

Die hier skizzierte Entwicklung hin zu einer selbstbewussten Betonung spanischer Musik ist kurvenreich, von Momenten der Euphorie und von retardierenden Momenten geprägt. Auch hier gilt Bermudos eingangs zitierter Satz, den ich verändert wiederholen möchte: Jede kulturhistorische Entwicklung bedeutet viele Dinge und hat viele Komponenten, bewerten wir diese ungeteilt, so entsteht große Verwirrung. Dass die politische Macht in Spaniens Musikdrucken

49 Ebda., fol. $135^{r}$.

50 Edward E. Lowinsky, »A Treatise on Text Underlay by a German Disciple of Francisco de Salinas", in: Festschrift Heinrich Besseler zum sechzigsten Geburtstag, hrsg. vom Insitut für Musikwissen-schaft der Karl-Marx-Universität (schriftleitung Eberhard Klemm), Leipzig 1961, S. 231. 
so überdeutlich erwähnt wird, signalisiert 1492 etwas anderes als 1556. Der mäzenatische Eifer der Katholischen Könige spiegelt sich in einer literarischen und wissenschaftlichen Produktion in der Zeit von etwa 1490 bis 1500 wider, die den nationalistischen Gründungswillen expliziert und sich ihm eindeutig widmet. Die Kulturpolitik Philipps II. folgt weniger dem Prinzip der Förderung als dem der Regulierung. Lasen sich die Widmungen von Nebrija und Encina im Sinne einer Danksagung, so stellen die von Bermudo oder Géry de Ghersem ${ }^{51}$ mehr schützende Selbstzensur oder Einsicht in die Notwendigkeit dar denn wirkliche Identifikation mit der und Liebe zur neuen Monarchie. ${ }^{52}$ Nicht dass man ihnen diese grundsätzlich absprechen könnte, dennoch hatten die Autoren Bermudo und Ghersem keine wirkliche Alternative. Man darf nicht ignorieren, dass im Zusammenhang mit Druckproduktion viele Entscheidungen getroffen werden, die vor allem den Rahmenbedingungen und nicht dem freien Gestaltungswillen des Autors unterliegen. Umso besser, denn nur in der Spannung zwischen Identifikationswunsch und -bedürfnis und den bekannten, aber auch den unwägbaren Vorgaben des Pragmatischen, Historischen und Konkreten vermag Autorität zu entstehen und sich zu entfalten.

Man muss daher jene Momente suchen, in denen das Substrat des historischen Bewusstseins die Verschränkung mit der Gegenwart eingeht. Das psychologische Bedürfnis, die historische Unbestimmheit in ein greifbares Objekt zu überführen, um dessen identifikatorisches Potenzial auszunutzen, zeigt sich in der Hispanisierung von Mythologie und in der Erhebung des Spanischen zur verbindlichen Autorität. Es liegt mit Sicherheit ein usurpatorisches Moment in diesen Umwidmungen. Doch wird dieser Vorwurf dadurch nichtig, dass die nationale Identität der Bewohner eines Gebietes wie der iberischen Halbinsel aus der Summe verschiedener Identitäten besteht; sie kann ihre über die Jahrhunderte entstandene multikulturelle Anreicherung nicht leugnen. Die Entstehung eines Nationalstaats ist wohl ein historisch verortbares Ereignis, die in Form einer chronologischen Folge von Handlungen beschreibbar ist. Diese Handlungen alleine generieren jedoch keinen Nationalstolz, sie bilden lediglich die historische Projektionsfläche, nach der sich Nationalstolz ausrichtet, so es der Nation gelingt, das historische Bewusstsein und das kollektive Gedächtnis zu treffen.

51 Géry de Ghersem gab den Messendruck seines Lehrers Philippe Rogier heraus.

$52 \mathrm{Vgl}$. in diesem Zusammenhang María A. Ester-Sala, "El mecenazgo de la nobleza en la música del siglo XVI", in: Nassarre 4 (1988), S. 37-58. Die Verfasserin subsumiert das Problem des Mäzenatentums unter die Dichotomie weltlich - geistlich, ohne eine differenziert historische Perspektive einzunehmen. Sie kommt dabei leider zu keinem Ergebnis. 